\title{
MATIZES DO GÓTICO: TRÊS SÉCULOS DE HORACE WALPOLE (2020), DE JÚLIO FRANÇA E LUCIANA COLUCCI (ORGS.)
}

Patricia Hradec

Patricia Hradec

Doutora em Letras pela Universidade Presbiteriana Mackenzie.

Membro do Grupo de Estudos do Gótico da Universidade Estadual do Rio de Janeiro (UERJ). httpS://lattes.cnpq.br/4021161559558051 https://orcid.org/0000-0001-5171-9566 
O GÓTICO E SUAS COMBINAÇÕES

Matizes do gótico: três séculos de Horace Walpole (2020), organizado por Júlio França e Luciana Colucci, conta com nove artigos que mapeiam a literatura gótica e usam como eixo central a obra seminal, 0 Castelo de Otranto (1764), de Horace Walpole (1717 - 1797).

É uma excelente leitura para aqueles que querem conhecer mais

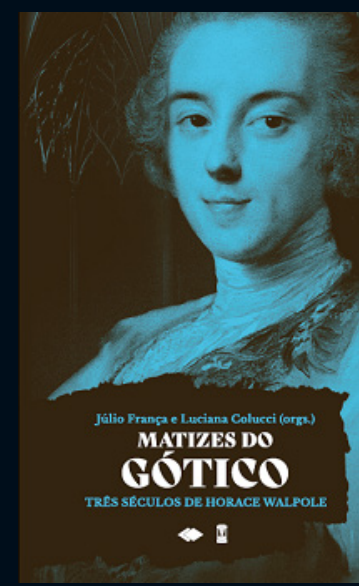
sobre o universo gótico, uma vez que abarca obras brasileiras e estrangeiras, literárias e fílmicas, tanto antigas quanto contemporâneas. Mas, é útil, também, para uma reflexão acerca do gótico e seus desdobramentos.

Logo de início, somos apresentados à nota editorial de Cid Vale Ferreira que atesta, não apenas a importância da literatura gótica no passado, mas principalmente, sua influência na literatura contemporânea. Seguindo a leitura, encontramos uma breve apresentação, escrita pelos organizadores, que explicam a concepção do livro e apresentam os nove artigos.

O primeiro intitulado "Entre vampiros e demônios: o sobrenatural do mundo de Horace Walpole", demonstra como a obra $O$ Castelo de Otranto (1764) está relacionada às figuras das sombras: o vampiro e o demônio/fantasma.

Alexander Meireles da Silva, inicia seu percurso descrevendo o que vem a ser o conceito de gótico, desde a Antiguidade, passando pela Idade Média, até chegar ao século XVIII, com a publicação da obra de Walpole. Se, no início, o termo gótico 
estava vinculado à superstição e ao demoníaco, após a obra de Walpole, o termo passa a ser a subversão da razão, conceito usado, até os dias de hoje, como balizador da literatura gótica.

Dentro desse contexto de subversão, temos duas figuras importantes. O vampiro, intimamente relacionado à literatura gótica, porém, ainda não estruturado como personagem literária, e o fantasma, que influenciou a obra de Walpole, pois já havia sido estabelecido enquanto personagem e figurado em diversas obras anteriores, incluindo as shakespearianas Hamlet (1603) e Macbeth (1606).

Por fim, somos apresentados ao relato conhecido como "o caso do fantasma de Cock Lane" que culminou com uma farsa exposta em um tribunal em 1763, indicando que o sobrenatural fazia parte do cotidiano, em oposição às ideias iluministas. E é nesse ambiente que floresce a obra de Walpole, que atesta a dicotomia: luz e escuridão e, apresenta o sobrenatural em oposição ao racional, marcando o início da literatura gótica.

O segundo artigo, escrito em língua inglesa e intitulado Two kinds of romance: generic hybridity and epistemological uncertainty in contemporary paranormal romance parte da noção do hibridismo entre os gêneros, para demonstrar como o gótico e a literatura contemporânea estão imbricadas.

Bill Hughes apresenta-nos os chamados paranormal romances, que buscam misturar personagens míticas e folclóricas com as personagens literárias constituintes da novel, apresentando uma nuance dos contos de fadas e fazendo um paralelo, na questão do hibridismo, com a obra O Castelo de Otranto (1764). 
Ele apresenta dois paranormal romances contemporâneos para jovens adultos, My Love Lies Bleeding (2009) de Alyxandra Harvey e The Iron King (2010) de Julie Kagawa. Nos dois romances, nosso mundo contemporâneo está interligado a outros mundos. No primeiro, temos como motivo literário o mundo vampírico; no segundo, temos o das fadas, porém, ambos criam uma rede intertextual com ênfase na modernidade, demonstrando duas forças antagônicas: natureza e humanidade, irracional e racional, velho e novo, no melhor estilo gótico.

O terceiro artigo, "Teratologias" faz um percurso pela filosofia, literatura e gótico. Apresenta-nos inicialmente a definição de teratologia para, em seguida, expor a etimologia de algumas palavras relacionadas.

Cido Rossi evoca o filósofo Sócrates e o poeta Homero como ponto de partida da reflexão. Também demonstra como Platão juntou conceitos e inventou mitos, como os de Toth, de Er e de Atlântida, importantes para a literatura e filosofia, além de criar o conceito de mimese, posteriormente aperfeiçoado por Aristóteles.

Dessa maneira, Rossi finaliza definindo o gótico como sendo a filosofia e a literatura, ou ainda, como teratologia. E, segundo ele, não há como fugir dessas três forças poderosas.

O quarto artigo, "Fantasmas brasileiros em O Animal Cordial" apresenta o gótico na obra cinematográfica contemporânea, com direção de Gabriela Amaral Almeida, de 2017.

Depois de apresentar uma breve trajetória do cinema de horror brasileiro, Claudio Zanini reflete sobre as mudanças culturais, tanto no público consumidor quanto em quem produz conteúdos ficcionais, 
gerando uma diversidade, nas quais a maquinaria gótica pode ser revisitada ou atualizada, justificando a obra fílmica apresentada.

A trama gira em torno de um restaurante que será invadido por dois assaltantes. Há diversos paradoxos que vão se desdobrando ao longo da análise. A violência urbana será o motivo para uma violência ainda maior e justificada nos moldes do slasher, fazendo com que $O$ Animal Cordial (2017) possa ser, também, um representante do gótico brasileiro.

Zanini atesta que essa obra apresenta os três elementos recorrentes do gótico: o retorno do passado em uma situação presente, personagens monstruosas e o locus horrendus. Ao final da leitura, temos a sensação de que o gótico está mais perto de nós do que imaginávamos, basta ter olhos e ouvidos atentos para perceber sua presença.

O quinto artigo escrito por Fernando Monteiro de Barros e intitulado "O gótico brasileiro em Úrsula (1859), de Maria Firmina dos Reis", é uma viagem ao Brasil do século XIX.

Apresenta um romance escrito por uma mulher, mas com as marcas do gótico masculino, no qual o patriarcalismo é destruído por potências femininas. Novamente, podemos observar os três elementos do gótico: a escravidão é o fantasma do passado que retorna no presente. O locus horrendus é o local opressor e, nesse caso, a casa-grande e a senzala. E a personagem monstruosa é o tio materno, o comendador Fernando, que tenta a todo custo desposar Úrsula.

Barros apresenta a intertextualidade explícita com $O$ Castelo de Otranto (1764), com o desfecho trágico e melancólico, mas com 
uma cor local, incorporando cenários e personagens do Brasil, como o senhor de engenho ou o barão do café em substituição ao aristocrata malvado.

Por fim, o artigo confirma a tese da antropofagia cultural difundida por Oswald de Andrade, misturando as diversas manifestações culturais, literárias, folclóricas e sociais, que influenciam nossa literatura.

Nesse sentido, o romance Úrsula (1859), de Maria Firmina dos Reis, é um excelente exemplo e talvez um caminho preliminar para o estudo da literatura gótica brasileira.

O sexto artigo "Figurações vampirescas em narrativas fantásticas de dois escritores angolanos: Ana Paula Tavares e José Eduardo Agualusa" investiga como a figura do vampiro está relacionada às narrativas fantásticas e qual é o seu ponto de contato com a literatura gótica.

Flavio García apresenta a análise de dois contos da coletânea, organizada por Pedro Sena-Lino e, intitulada Contos de Vampiros (2009). "O mistério da Rua da Missão" de Ana Paula Tavares e "M. de malária" de José Eduardo Agualusa, tem em comum a transgressão, pois quebram não apenas a figuração do vampiro tradicional, como também, o mundo cotidiano que conhecemos. Uma das personagens do conto "O mistério da Rua da Missão" fica no entrelugar, não estando nem morta e nem viva, assim como um vampiro subversivo.

O conto “M. de malária" também apresenta uma personagem subversiva, não porque está, a princípio, morta-viva, mas porque busca mudar sua existência prévia, organizando uma nova vida 
com dinheiro usurpado de um cliente. As duas obras apresentam as ressignificações vampíricas contemporâneas, e compõe as leituras para se ampliar horizontes e refletir sobre os vampiros e o gótico.

O sétimo artigo, escrito por Júlio França e intitulado "O Gótico e a questão moral da empatia", demonstra como as obras artísticas e literárias conseguem desenvolver nos leitores emoções diversas.

Uma dessas emoções é a empatia, ligada não apenas ao físico, mas também à moral. $\mathrm{O}$ ponto alto desse artigo é o estudo de caso da série Black Mirror, o terceiro episódio, da terceira temporada, intitulado Shut up and dance (2016), quando a empatia é colocada em jogo de acordo com nossos juízos morais. Por fim, traz uma reflexão entre empatia, piedade e compaixão, sentimentos praticados, também, ao lermos uma história gótica.

O oitavo artigo intitulado "Horace Walpole: vida \& obra revisitadas, um esboço crítico", analisa o fundador da literatura gótica inglesa. Luciana Colucci irá descrever não apenas as características psicológicas, mas também seus interesses e seu modo de vida da época, influenciando a literatura gótica subsequente.

Há diversas fotos que corroboram com todo o estudo minucioso feito por Colucci. Ela irá destacar duas obras de Walpole: The Mysterious Mother (1768) e The Hieroglyphic Tales (1772, publicado em 1785) que demarcam os estudos sobre a dramatização do romance. Por fim, o percurso nos levará às reflexões sobre o hibridismo cultural e textual de Walpole e todo o seu legado.

O nono e último artigo, intitulado "Estátuas terríficas: figurações humanas, objetos insólitos", escrito por Marisa Martins 
Gama-Khalil, expõe alguns exemplos insólitos de estátuas que ganham vida.

Gama-Khalil apresenta quatro obras distintas relacionadas às estátuas: o mito de Pigmaleão contado por Ovídio, no início da Era Cristã e por Bulfinch no Livro de ouro da Mitologia: Histórias de deuses e heróis ([1855] 2014), o conto popular "O fiel Dom José" recolhido por Luís da Câmera Cascudo e publicado em Contos Tradicionais do Brasil ([1946] 1986), o conto "A Vênus de Ille" ([1837] 2004) de Prosper Mérimée e "O príncipe Feliz" ([1888] 2005) de Oscar Wilde.

Muitas estátuas são compostas por diversos elementos e detalhes para trazer uma certa vivificação em quem as observam e dessa maneira, não desencorajam o fascínio que elas causam em seus espectadores e criadores.

Essas quatro obras, distintas entre si e provenientes de diferentes lugares e épocas, apresentam o gótico, na medida em que subvertem nossa percepção de algo estático que passa a ser animado, desestruturando o cotidiano e por vezes, trazendo o horror.

O livro ainda conta com outras seções. A "Sobre os autores", dános um panorama das pesquisas e dos grupos que cada um dos autores participa. O "Índice de ilustrações de abertura", dá os créditos para cada foto ou ilustração contida na abertura de cada capítulo. Finalmente, termina com as "Notas" separadas de cada artigo, que amplia e oferece explicações detalhadas para melhorar o entendimento sobre os conceitos e as obras apresentados ao longo da leitura.

Ao término, teremos um panorama sobre a diversidade da literatura gótica, não apenas do passado, mas também do presente. 
Diversas obras continuam revisitando o maquinário gótico, de maneira mais ou menos explícita e de acordo com os interesses dos leitores.

Se o gótico é o próprio texto, conforme afirmou Rossi, cabe a cada um dos leitores se atentar e perceber o grau de comprometimento de cada obra apresentada nesse contexto, formando assim as Matizes do gótico.

\section{REFERÊNCIAS}

FRANÇA, Júlio; COLUCCI, Luciana (Orgs.). Matizes do gótico: três séculos de Horace Walpole. São Paulo: Editora Sebo Clepsidra, 2020. 